\title{
Impact of functional status at six months on long term survival in patients with ischaemic stroke: prospective cohort studies
}

\author{
Karsten Bruins Slot, clinical research fellow, ${ }^{1}$ Eivind Berge, senior consultant, ${ }^{1}$ Paul Dorman, consultant \\ neurologist, ${ }^{2}$ Steff Lewis, medical statistician, ${ }^{3}$ Martin Dennis, professor, ${ }^{3}$ Peter Sandercock, professor, ${ }^{3}$ on \\ behalf of the Oxfordshire Community Stroke Project, the International Stroke Trial (UK), and the Lothian \\ Stroke Register
}

\begin{abstract}
'Department of Internal Medicine Ullevaal University Hospital, NO0407 Oslo, Norway

${ }^{2}$ Department of Neurology, Newcastle General Hospital, Newcastle upon Tyne

${ }^{3}$ Department of Clinical Neurosciences, Western General Hospital, Edinburgh

Correspondence to: $\mathrm{K}$ Bruins Slot karsten.bruins.slot@medisin.uio. no
\end{abstract}

doi:10.1136/bmj.39456.688333.BE

\section{ABSTRACT}

Objective To estimate the impact on long term survival of functional status at six months after ischaemic stroke. Design Prospective cohort study.

Settings Three cohorts: Oxfordshire community stroke project, Lothian stroke register, and the first international stroke trial (in the United Kingdom).

Participants 7710 patients with ischaemic stroke registered between 1981 and 2000 and followed up for a maximum of 19 years.

Main outcome measures Functional status at six months after stroke assessed with modified Rankin scale or "two simple questions." Mortality during follow-up. Survival analysis with Kaplan-Meier curves, log rank test, and Cox's regression model.

Results In a combined analysis of all three cohorts, among patients who survived to assessment six months after the index stroke, the subsequent median length of survival among those independent in daily living and those dependent was 9.7 years (95\% confidence interval 8.9 to 10.6) and 6.0 years (5.7 to 6.4), respectively. In a combined analysis of the Oxfordshire and Lothian cohorts, subsequent median survival fell progressively from 12.9 years (10.0 to 15.9$)$ for patients with a Rankin score of $0-1$ at six months after the stroke to 2.5 years (1.4 to 3.5) for patients with a Rankin score of 5. All previously stated differences in median survival were significant (log rank test $P<0.001)$. The influence of functional outcome on survival remained significant $(P<0.05)$ in each cohort after adjustment for relevant covariates (such as age, presence of atrial fibrillation, visible infarct on computed tomography, subtype of stroke) in a Cox's regression model.

Conclusion Functional status six months after an ischaemic stroke is associated with long term survival. Early interventions that reduce dependency at six months might have positive effects on long term survival.

\section{INTRODUCTION}

The global burden of stroke is large, yet there are still gaps in our knowledge. ${ }^{12}$ Although there are now reliable estimates on outcome in the early months and years after an ischaemic stroke, we know much less on long term survival and what influences it. ${ }^{3}$ This lack of information is important for many reasons. If, for example, functional status several months after a stroke has a major influence on long term survival, this will affect clinical practice (including our communication with patients), our estimates of the future global burden and costs of stroke, and the planning of health care and research.

We estimated the relative and absolute effects of the level of functional status at six months on long term survival in three large prospective cohorts of patients with ischaemic stroke.

\section{METHODS}

We sought data from three cohorts of patients with an ischaemic stroke recruited in the United Kingdom: the Oxfordshire community stroke project, the Lothian stroke register, and the UK patients enrolled in the first international stroke trial.

\section{Initial data collection and clinical follow-up}

Oxfordshire community stroke project-This project was a community based incidence study of stroke and transient ischaemic attacks. ${ }^{4}$ Patients were registered from 1981 to 1986 . Details on the study population, clinical definitions, methods of assessment, and investigations have been described in detail elsewhere. ${ }^{4} \mathrm{~A}$ study neurologist assessed all patients as soon as possible after the onset of symptoms. Baseline characteristics were recorded in a standardised form. Trained study nurses followed up surviving patients at one, six, and 12 months from the date of stroke onset and then annually for up to five years. When possible, a study physician assessed survivors at the end of clinical follow-up.

Lothian stroke register - The register was established to collect data on patients with suspected stroke, transient ischaemic attacks, or retinal artery occlusion from those attending outpatient clinics and admitted to one 
hospital in Edinburgh. The registration began in 1990 and continued to 2000. One of the study's stroke physicians examined the patient and collected baseline data as soon as possible after symptom onset. Patients were followed up at $6,12,24$, and 36 months from the date of symptom onset. Follow-up data were obtained either by telephone interview, postal questionnaire, or home or clinic visits.

First international stroke trial-This was a randomised trial of aspirin, subcutaneous heparin, both, or neither, started within 48 hours of onset of ischaemic stroke. ${ }^{5} \mathrm{~A}$ total of 19435 patients were enrolled from 1991 to 1997, of whom 6257 (32\%) were enrolled by hospitals in the UK. Baseline data were collected before randomisation in the trial. Final clinical follow-up at six months was by postal questionnaire or telephone interview or, in a few cases, during a clinic visit.

\section{Collection of long term survival data}

At the end of planned clinical follow-up in each of the three cohorts, notes of patients who were still alive were "flagged" at the NHS central register of the Office for National Statistics (ONS). On the death of a cohort participant, ONS forwarded notification of the death and a copy of the death certificate to the study office. Patients who were not reported to have died before the close of follow-up on 16 November 2000 were assumed to be alive.

\section{Classification of ischaemic strokes}

In all three cohorts, ischaemic stroke was diagnosed with a combination of clinical criteria and brain imaging or autopsy. As these examinations excluded intracerebral haemorrhages and conditions mimicking stroke (for example, subdural haematoma or cerebral tumour), the presence of visible infarction on imaging (or autopsy) was not necessary for the diagnosis of ischaemic stroke. According to criteria from the Oxfordshire community stroke project classification, we used the clinical features to subdivide diagnosis into total anterior circulation infarct, partial anterior circulation infarct, lacunar infarct, posterior circulation infarct, or, when no clinical subtype could be assigned, cerebral infarct of indeterminate clinical subtype. ${ }^{6}$

\section{Definition of outcomes}

In the Oxfordshire and Lothian cohorts the level of function at six months after stroke onset was assessed by the modified Rankin scale. ${ }^{7}$ In the international stroke trial this was done by means of the "two simple questions" that were developed to assess functional outcome after stroke in large scale trials. ${ }^{8}$ The patients (directly or through relatives) were asked if they had needed help from another person to perform everyday activities within the past two weeks (such as bathing, feeding, walking, dressing, or use of the toilet). The Rankin score and the two simple questions are methods that both have good validity and reliability between observers and correspond well with each other. ${ }^{710} \mathrm{We}$ defined an independent state as Rankin score of $0-2$ and a dependent state as score of 3-5. The international stroke trial classified patients who reported not needing any help to perform everyday activities within the past two weeks as independent.

\section{Statistical analysis}

We estimated survival curves in the three cohorts with the Kaplan-Meier product limit technique. We used median rather than mean to describe and compare survival from the six month assessment of functional outcome in each cohort as means are hugely influenced by the length of follow-up (which varied in the three cohorts). We performed univariate and multivariate analyses of risk factors with Cox's proportional hazards models. Data from patients who were dead at six months after stroke onset were not entered in the models as we were interested only in the impact of functional status at six months on subsequent survival. We entered age and systolic blood pressure as continuous variables. The proportionality assumption was verified with the Schoenfeld test and did not seem to be violated. ${ }^{11}$ We used SPSS software (version 13.0 for Mac OS X) for the statistical analysis.

\section{RESULTS}

\section{Oxfordshire cohort}

This study registered 675 patients with first ever stroke. We excluded $136(20 \%)$. Of these, $130 \mathrm{did}$ not have a diagnosis of ischaemic stroke (33 had a subarachnoid haemorrhage, 65 a primary intracerebral haemorrhage, and 32 a stroke of undefined pathological type). We excluded six other patients in whom there was an apparent error in the recording of the date of death. The 539 remaining patients had a definite $(n=434)$ or probable $(\mathrm{n}=105)$ ischaemic stroke.

Table 1 shows the baseline characteristics and vital and dependency status at six months. Patients were followed up for a maximum of 19 years. Figure 1 shows

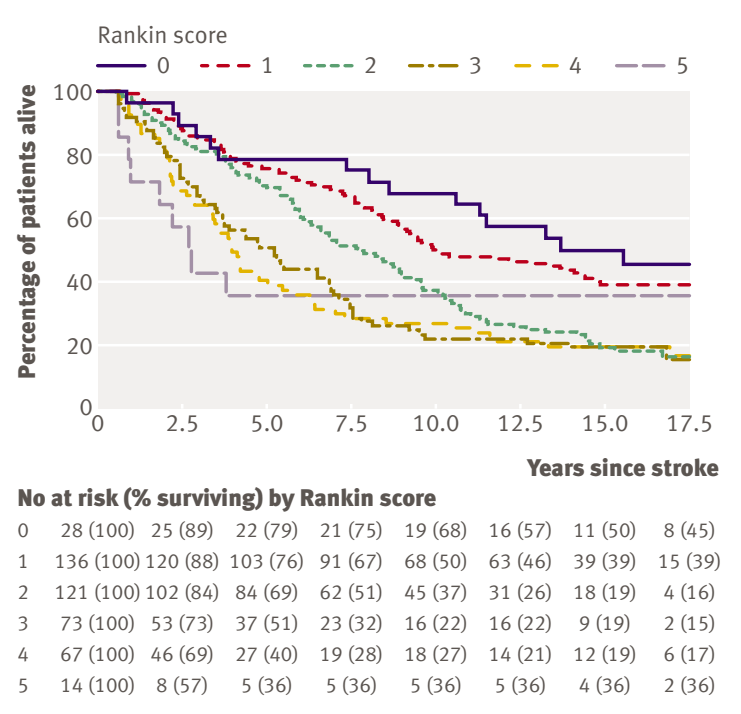

Fig 1 Oxfordshire cohort. Long term survival of patients in each category of functional status (Rankin score 0-5) from assessment at six months after index stroke 
survival curves for patients stratified by Rankin score 0 5 at six months. There was a significant trend (log rank test, $\mathrm{P}<0.001)$ of decreasing survival with increasing Rankin score at six months. We entered all baseline variables in table 1 and functional status at six months after stroke onset into a univariate and multivariate Cox's regression model (table 2). Both the separate Rankin scores and level of dependency at six months had a significant effect $(\mathrm{P}<0.05)$ on subsequent survival in the multivariate analyses. The more dependent a patient was at six months, the shorter their subsequent survival. Age and the presence of atrial fibrillation on examination also had a significant negative effect $(\mathrm{P}<0.001)$ on survival. We used a similar model to analyse the impact of the Rankin scores at one month after stroke onset. This gave generally the same results as those of the Rankin scores at six months (data not shown).

\section{Lothian cohort}

In all, 4455 patients with a stroke, transient ischaemic attack, retinal artery occlusion, or other diagnosis were entered on the register in 1990-9. We sought patients with relevant clinical features and computed tomography or magnetic resonance imaging at baseline indicating an ischaemic infarct $(\mathrm{n}=1547)$ or patients with normal results on computed tomography or magnetic resonance imaging at baseline and a clinical

Table 1|Baseline characteristics and status of patients at six months after stroke onset in three cohorts. Figures are numbers (percentages) of patients unless stated otherwise

\begin{tabular}{|c|c|c|c|c|}
\hline & OCSP $(n=539)$ & LSR $(n=2054)$ & IST-1 $(n=5117)$ & $\begin{array}{l}\text { All cohorts } \\
(n=7710)\end{array}$ \\
\hline Mean (SD) age (years) & $73(12)$ & $68(13)$ & $73(11)$ & $72(12)$ \\
\hline Men & $269(50)$ & $1087(53)$ & $2683(52)$ & $4039(52)$ \\
\hline Mean (SD) systolic BP (mm Hg) & $162(33)$ & $157(30)$ & $158(27)$ & $158(28)$ \\
\hline Atrial fibrillation on baseline ECG & $84(16)^{\star}$ & 259 (13)† & $1012(20) \ddagger$ & $1355(18)$ \\
\hline CT performed at baseline & $472(88)$ & $2054(100)$ & $2499(49) \S$ & $5025(65)$ \\
\hline Visible infarct on baseline CT & $263(56)$ & $1245(61)$ & $1639(66) \S$ & $3147(63)$ \\
\hline \multicolumn{5}{|l|}{ Medication before stroke: } \\
\hline Antiplatelet & $17(4)$ & $641(31)$ & $1281(25) \pi$ & $1939(25)$ \\
\hline Anticoagulant & $6(1)$ & $84(4)$ & $39(1)^{\star \star}$ & $129(2)$ \\
\hline \multicolumn{5}{|l|}{ Stroke syndrome: } \\
\hline $\mathrm{TACl}$ & $92(17)$ & $246(12)$ & $1437(28)$ & $1775(23)$ \\
\hline $\mathrm{PACl}$ & $182(34)$ & 811 (39) & $2072(40)$ & $3065(40)$ \\
\hline $\mathrm{LACl}$ & $137(25)$ & $546(27)$ & $1042(20)$ & $1725(22)$ \\
\hline $\mathrm{POCl}$ & $128(24)$ & $342(17)$ & $551(11)$ & $1021(13)$ \\
\hline Indeterminate subtype & - & $109(5)$ & $15(0.3)$ & $124(2)$ \\
\hline \multicolumn{5}{|l|}{ Status at six months: } \\
\hline Independent & $285(53)$ & $1142(56)$ & $1098(22)$ & $2525(33)$ \\
\hline Dependent & $154(29)$ & 604 (29) & $2678(52)$ & $3436(45)$ \\
\hline Dead & $100(18)$ & 308 (15) & $1341(26)$ & 1749 (23) \\
\hline
\end{tabular}

$\mathrm{OCSP}=0$ xfordshire community stroke project; $\mathrm{LSR}=$ Lothian stroke register; IST-1=first international stroke trial; $\mathrm{ECG}=$ electrocardiogram; $\mathrm{CT}=$ computed tomography; $\mathrm{TACl}=$ total anterior circulation infarct; $\mathrm{PACl}=$ partial anterior circulation infarct; $\mathrm{LACl}=$ lacunar infarct; $\mathrm{POCl}=$ posterior circulation infarct.

*Missing data in 11 patients.

†Not recorded in 288 patients.

$\ddagger$ Not recorded in 348 patients during pilot phase of trial.

$\S$ Diagnosis confirmed in remainder by CT after randomisation or by autopsy. "Visible infarct on CT" refers only to those scans performed before randomisation.

TNot recorded in 348 patients during pilot phase and subsequently recorded only if aspirin was used.

${ }^{\star *}$ Not recorded in 153 patients during pilot phase and use subsequently recorded only if heparin was used.

BMJ | ONLINE FIRST | bmj.com

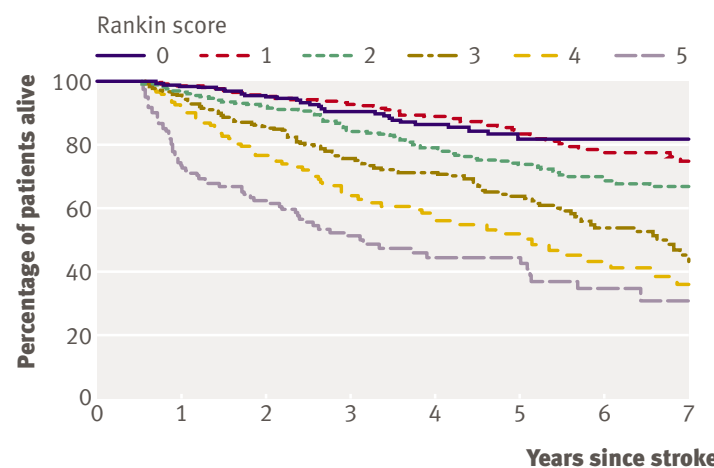

No at risk (\% surviving) by Rankin score

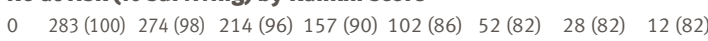
$404(100) 392(99) \quad 318(95) 253(93) 181(89) 117(83) \quad 83(79) \quad 46(75)$ $455(100) \quad 435(97) \quad 373(92) 289(84) 224(79) \quad 156(74) \quad 97(69) \quad 55(67)$ $360(100) \quad 342(96) 265(85) 202(76) 140(71) \quad 91(64) \quad 55(54) \quad 22(43)$ $122(100) \quad 112(92) \quad 83(77) \quad 61(64) \quad 47(57) \quad 32(52) \quad 20(43) \quad 13(36)$ $122(100) \quad 89(74) \quad 67(62) \quad 43(51) \quad 28(44) \quad 24(44) \quad 12(34) \quad 6(31)$

Fig 2 Lothian cohort. Long term survival of patients in each category of functional status (Rankin score 0-5) from assessment at six months after index stroke

diagnosis of a probable $(n=320)$ or definite stroke $(n=629)$. We excluded $442(18 \%)$ of these patients from our final analysis; 414 patients whose first follow-up occurred (for organisational reasons) at 12 months or later (hence functional status at six months was not known), seven patients who were lost to follow-up by six months, one patient in whom there was an apparent error in the recording of the date of stroke onset, and 20 patients who had refused further participation in the study at some point after entry. In our final analyses we therefore had data on 2054 patients.

Table 1 shows baseline characteristics and vital and dependency status at six months. Patients were followed up for a maximum of 9.7 years. Figure 2 shows survival curves. There was a significant trend (log rank test, $\mathrm{P}<0.001)$ of a decrease in survival with an increase in Rankin score at six months. We entered the baseline variables in table 1 and the functional status at six months after stroke onset in a univariate and multivariate Cox's regression model (table 3). Both the separate Rankin scores and the level of dependency had a significant effect $(\mathrm{P}<0.001)$ on survival in multivariate analyses. Age, sex, and the presence of atrial fibrillation also had significant negative effects $(\mathrm{P}<0.05)$ on survival.

\section{International stroke trial cohort}

A probable or definite ischaemic stroke was diagnosed in 5139 patients recruited in the UK. We excluded 22 $(0.4 \%)$ patients from the final analysis as we did not know their dependency status at six months $(n=20)$ or there was an error in the recording of the date of death $(n=2)$. Table 1 shows the baseline characteristics. Among the patients with probable or definite ischaemic stroke, $49 \%$ underwent computed tomography before randomisation into the trial; in the remainder the diagnosis was confirmed either by computed tomography after randomisation or by autopsy. Figure 3 shows the survival curves for patients who were 
Table 2 | Univariate and multivariate Cox's regression analyses of baseline variables for patients alive at six months after stroke onset in Oxfordshire community stroke project. Figures are hazard ratios ( $95 \%$ confidence intervals)

\begin{tabular}{|c|c|c|}
\hline Variable & Univariate analysis & Multivariate analysis \\
\hline Age & $1.05(1.04 \text { to } 1.07)^{\star \star \star}$ & $1.04(1.03 \text { to } 1.06)^{\star \star \star}$ \\
\hline Male sex & $0.99(0.80$ to 1.24$)$ & $1.22(0.98$ to 1.54$)$ \\
\hline Mean systolic BP & $1.00(1.00$ to 1.00$)$ & $1.00(1.00$ to 1.00$)$ \\
\hline Atrial fibrillation & $1.94(1.43 \text { to } 2.65)^{\star \star \star}$ & $1.85(1.33 \text { to } 2.58)^{\star \star \star}$ \\
\hline Visible infarct on CT & $1.19(0.96$ to 1.49$)$ & $1.13(0.89$ to 1.43$)$ \\
\hline Antiplatelet use before stroke & 1.08 (0.60 to 1.92$)$ & $0.95(0.52$ to 1.73$)$ \\
\hline Anticoagulant use before stroke & 0.62 (0.20 to 1.93$)$ & $0.64(0.19$ to 2.14$)$ \\
\hline \multicolumn{3}{|l|}{ Stroke syndrome: } \\
\hline $\mathrm{LACl}$ & 1 & 1 \\
\hline $\mathrm{PACl}$ & $1.05(0.80$ to 1.38$)$ & $0.93(0.70$ to 1.24$)$ \\
\hline $\mathrm{POCl}$ & $1.12(0.84$ to 1.51$)$ & $1.14(0.84$ to 1.55$)$ \\
\hline $\mathrm{TACl}$ & 1.29 (0.84 to 1.97$)$ & $0.90(0.56$ to 1.45$)$ \\
\hline \multicolumn{3}{|l|}{ Rankin score (at six months) $\dagger$} \\
\hline 0 & 1 & 1 \\
\hline 1 & $1.25(0.72$ to 2.17$)$ & $1.20(0.69$ to 2.08$)$ \\
\hline 2 & $2.06(1.19 \text { to } 3.55)^{*}$ & $1.54(0.90$ to 2.67$)$ \\
\hline 3 & $2.69(1.53 \text { to } 4.75)^{\star \star \star}$ & $2.04(1.15 \text { to } 3.63)^{\star}$ \\
\hline 4 & $2.78(1.57 \text { to } 4.93)^{\star \star \star \star}$ & $1.82(1.02 \text { to } 3.26)^{\star}$ \\
\hline 5 & 2.12 (0.93 to 4.83$)$ & $1.25(0.54$ to 2.90$)$ \\
\hline Functionally dependent & $1.76(1.40 \text { to } 2.20)^{\star \star \star}$ & $1.38(1.09 \text { to } 1.75)^{\star \star \star} t$ \\
\hline \multicolumn{3}{|c|}{$\begin{array}{l}\mathrm{CT}=\text { computed tomography; } \mathrm{LACl}=\text { lacunar infarct; } \mathrm{PACl}=\text { partial anterior circulation infarct; } \mathrm{POCl}=\text { posterior } \\
\text { circulation infarct; } \mathrm{TACl}=\text { total anterior circulation infarct. } \\
{ }^{\star} \mathrm{P}<0.05 * \star \star \mathrm{P}<0.001 \\
\text { †Overall } \mathrm{P} \text { values of Rankin score (at six months): univariate analysis } \mathrm{P}<0.001 \text { and multivariate analysis } \mathrm{P}=0.00 \\
\text { †Separate multivariate analysis without entering the variable "Rankin score (at six months)." }\end{array}$} \\
\hline
\end{tabular}

independent and dependent at six months after randomisation. There was a significant effect (log rank test, $\mathrm{P}<0.001$ ) of the level of dependency on survival. We entered all baseline variables in table 1 and the functional status at six months after stroke onset in a Cox's regression model (table 4). The level of dependency at six months had a significant effect $(\mathrm{P}<0.001)$ on survival in the multivariate analysis. Age, sex, presence of atrial fibrillation on baseline examination, use of aspirin before the stroke, and stroke subtype were also significant $(\mathrm{P}<0.05)$.

\section{Pooled estimate of median survival}

Table 5 shows estimates of the median survival time, subdivided by Rankin score, based on the combined dataset of the Lothian and Oxfordshire cohorts. There was a significant trend ( $\log$ rank test $\mathrm{P}<0.001)$ of decreasing median survival with increasing Rankin score. Table 5 also gives estimates of median survival for independent and dependent patients based on data from all three cohorts combined. This difference was highly significant (log rank test, $\mathrm{P}<0.001)$.

\section{Survival among cohorts recruited in different time periods}

We compared survival in all three cohorts among independent and dependent patients who were enrolled during three different time periods (1981-6, 1990-4, and 1995-2000). Estimated median survival for patients who were dependent at six months after stroke onset was 4.2 years among those recruited during 1981-
6 and 6.5 years among those recruited during 1990-4 No accurate estimations can be given for the period 1995-2000, as over half of both dependent and independent patients were alive at the end of follow-up.

We also analysed the influence of year of recruitment on two year survival in the Lothian and international stroke trial cohorts. We compared the proportions of patients who were alive at two years. Among patients recruited in 1990-4 and 1995-2000 who were independent at the six month assessment the proportions alive at two years were $90 \%$ and $93 \%$, respectively. Among those recruited in the same years who were dependent at the six month assessment the proportions alive at two years were $80 \%$ and $81 \%$. These differences were not significant.

We also entered the date of stroke onset (or date of randomisation in the international stroke trial cohort) as a variable in the multivariate Cox's regression analyses of each cohort. Date of stroke onset was not a significant variable in the Oxfordshire $(\mathrm{P}=0.45)$ and Lothian $(\mathrm{P}=0.083)$ cohorts. The date of randomisation was a significant variable $(\mathrm{P}<0.001)$ in the international stroke trial cohort. A multivariate Cox's regression analysis in the international stroke trial cohort showed that, among patients recruited in 1995-7, survival was significantly greater than among those recruited in 1991-4 ( $\mathrm{P}<0.001$; hazard ratio $0.82,95 \%$ confidence interval 0.73 to 0.91 ).

\section{DISCUSSION}

This study provides robust estimates of the relative and absolute effects that the level of dependency six months after an ischaemic stroke has on subsequent long term survival. The impact of functional status on median survival was substantial and remained significant after adjustment for baseline variables known to influence prognosis. The findings were consistent in size and direction across these three, somewhat different, cohorts of ischaemic stroke patients.

We were surprised to see the poor survival of patients with a Rankin score of 4-5. The five year survival for

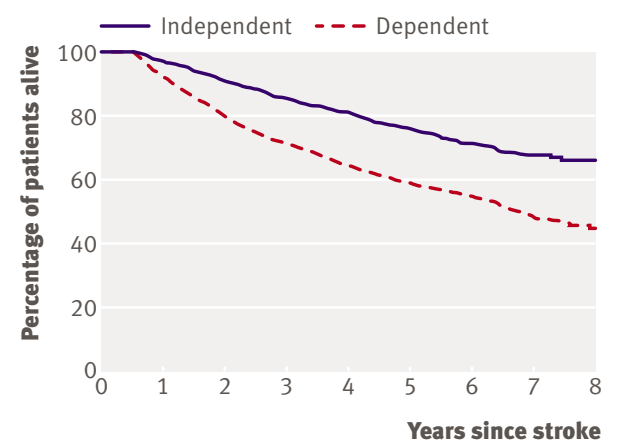

No at risk (\% surviving)

Independent $1098(100) \quad 1001(91) \quad 894(81) \quad 410(71) \quad 183(68)$ Dependent $2678(100) \quad 2148(80) \quad 1726(64) \quad 734(55) \quad 48(45)$

Fig 3 International stroke trial cohort. Long term survival of patients who were alive and dependent or independent from assessment at six months after randomisation 
Table 3 | Univariate and multivariate Cox's regression analyses of baseline variables for patients alive at six months after stroke onset in Lothian stroke register. Figures are hazard ratios ( $95 \%$ confidence intervals)

\begin{tabular}{|c|c|c|}
\hline Variable & Univariate analysis & Multivariate analysis \\
\hline Age & $1.06(1.05 \text { to } 1.07)^{\star \star \star}$ & $1.05(1.04 \text { to } 1.06)^{\star \star \star}$ \\
\hline Male sex & 1.05 (0.87 to 1.26$)$ & $1.33(1.08 \text { to } 1.64)^{\star}$ \\
\hline Mean systolic BP & 1.00 (0.99 to 1.01$)$ & 1.00 (1.00 to 1.00$)$ \\
\hline Atrial fibrillation & $3.00(2.37 \text { to } 3.80)^{\star \star \star}$ & $1.65(1.25 \text { to } 2.17)^{\star}$ \\
\hline Visible infarct on $\mathrm{CT}$ & $1.22(1.01 \text { to } 1.47)^{\star}$ & 1.09 (0.89 to 1.35$)$ \\
\hline Antiplatelet use before stroke & $1.48(1.22 \text { to } 1.80)^{\star \star \star}$ & $1.31(1.07 \text { to } 1.62)^{\star}$ \\
\hline Anticoagulant use before stroke & 1.07 (0.63 to 1.82$)$ & $0.91(0.51$ to 1.60$)$ \\
\hline \multicolumn{3}{|l|}{ Stroke syndrome†: } \\
\hline $\mathrm{LACl}$ & 1 & 1 \\
\hline $\mathrm{PACl}$ & $1.57(1.24 \text { to } 2.00)^{\star \star \star}$ & $1.32(1.02 \text { to } 1.72)^{\star}$ \\
\hline $\mathrm{POCl}$ & 1.01 (0.74 to 1.39$)$ & $1.16(0.83$ to 1.62$)$ \\
\hline $\mathrm{TACl}$ & $2.25(1.63 \text { to } 3.11)^{\star \star \star}$ & $1.22(0.83$ to 1.79$)$ \\
\hline Indeterminate subtype & $1.25(0.77$ to 2.04$)$ & 1.14 (0.68 to 1.92$)$ \\
\hline \multicolumn{3}{|l|}{ Rankin score (at six months)‡: } \\
\hline 0 & 1 & 1 \\
\hline 1 & 1.01 (0.66 to 1.56$)$ & $0.98(0.63$ to 1.54$)$ \\
\hline 2 & $1.66(1.12 \text { to } 2.46)^{\star}$ & $1.74(1.16 \text { to } 2.61)^{\star}$ \\
\hline 3 & $2.86(1.95 \text { to } 4.20)^{\star \star \star}$ & $2.58(1.73 \text { to } 3.87)^{\star \star \star}$ \\
\hline 4 & $4.11(2.69 \text { to } 6.30)^{\star \star \star}$ & $3.89(2.48 \text { to } 6.12)^{\star \star \star}$ \\
\hline 5 & $6.41(4.23 \text { to } 9.73)^{\star \star \star}$ & $4.98(3.15 \text { to } 7.88)^{\star \star \star}$ \\
\hline Functionally dependent & $2.87(2.38 \text { to } 3.46)^{\star \star \star}$ & $2.43(1.96 \text { to } 3.01)^{\star * \star} \S$ \\
\hline
\end{tabular}

$\mathrm{CT}=$ computed tomography; $\mathrm{LACl}=$ lacunar infarct; $\mathrm{PACl}=$ partial anterior circulation infarct; $\mathrm{POCl}=$ posterior circulation infarct; TACl=total anterior circulation infarct.

${ }^{*} \mathrm{P}<0.05,{ }^{* * * \mathrm{P}<0.001}$

tOverall $P$ values of stroke syndrome: univariate analysis $P<0.001$ and multivariate analysis $P=0.32$.

$\ddagger$ Overall $P$ values of Rankin score (at six months): univariate and multivariate analysis $P<0.001$.

§Separate multivariate analysis without variable "Rankin score (at six months)."

Table 4 | Univariate and multivariate Cox regression analyses of baseline variables for patients alive at six months after randomisation into the first international stroke trial. Figures are hazard ratios ( $95 \%$ confidence intervals)

\begin{tabular}{lcc} 
Variable & Univariate analysis & Multivariate analysis \\
Age & $1.07(1.06 \text { to } 1.07)^{\star \star \star}$ & $1.07(1.06 \text { to } 1.07)^{\star \star \star}$ \\
\hline Male sex & $0.97(0.88$ to 1.07$)$ & $1.42(1.28 \text { to } 1.58)^{\star \star \star}$ \\
\hline Mean systolic BP & $1.00(1.00$ to 1.00$)$ & $1.00(1.00$ to 1.00$)$ \\
\hline Atrial fibrillation & $1.64(1.45 \text { to } 1.86)^{\star \star \star}$ & $1.16(1.02 \text { to } 1.32)^{\star}$ \\
\hline Visible infarct on CT & $0.95(0.85$ to 1.06$)$ & $1.05(0.94$ to 1.17$)$ \\
\hline Antiplatelet use before stroke & $1.21(1.08 \text { to } 1.35)^{\star}$ & $1.17(1.04 \text { to } 1.31)^{\star}$ \\
\hline Anticoagulant use before stroke & $0.71(0.35$ to 1.42$)$ & $0.62(0.31$ to 1.24$)$ \\
\hline Stroke syndrome†: & $1.25(1.09 \text { to } 1.42)^{\star}$ & $1.15(1.01 \text { to } 1.31)^{\star}$ \\
\hline LACl & $0.98(0.81$ to 1.19$)$ & $1.04(0.86$ to 1.26$)$ \\
\hline PACl & $1.44(1.24 \text { to } 1.66)^{\star \star \star}$ & $1.23(1.06 \text { to } 1.43)^{\star}$ \\
\hline POCl & $0.28(0.07$ to 1.14$)$ & $0.36(0.09$ to 1.43$)$ \\
\hline TACl & $1.91(1.68 \text { to } 2.16)^{\star \star \star}$ & $1.63(1.43 \text { to } 1.85)^{\star \star \star}$ \\
\hline Indeterminate subtype & & \\
\hline Functionally dependent (at six & & 1 \\
\hline months) & & \\
\hline
\end{tabular}

$\mathrm{CT}=$ computed tomography; $\mathrm{LACl}=$ lacunar infarct; $\mathrm{PACl}=$ partial anterior circulation infarct; $\mathrm{POCl}=$ posterior circulation infarct; $\mathrm{TACl}=$ total anterior circulation infarct.

${ }^{*} \mathrm{P}<0.05$, *** $\mathrm{P}<0.001$.

†Overall $P$ values of stroke syndrome: univariate analysis $P<0.01$ and multivariate analysis $P=0.03$.
Table 5 |Combined analysis estimating effect of functional status at six months on subsequent median survival

Functional status

Median survival (years) $(95 \% \mathrm{Cl})$

Rankin score in Oxfordshire and Lothian cohorts (No of patients):

\begin{tabular}{lc}
\hline $0(311)$ & \multicolumn{1}{c}{$>15^{\star}$} \\
\hline $1(540)$ & $11.7(8.4$ to 14.9$)$ \\
\hline $2(576)$ & $8.4(7.6$ to 9.3$)$ \\
\hline $3(433)$ & $6.0(5.2$ to 6.8$)$ \\
\hline $4(189)$ & $3.7(2.9$ to 4.6$)$ \\
\hline $5(136)$ & $2.5(1.4$ to 3.5$)$ \\
\hline All three cohorts (No of patients): & $9.7(8.9$ to 10.6$)$ \\
\hline Independent (2525) & $6.0(5.7$ to 6.4$)$ \\
\hline
\end{tabular}

*Exact median not given as less than half of patients died during follow up. Median survival 12.9 years $(95 \% \mathrm{Cl} 10.0$ to 15.9$)$ for Rankin 0 and 1 combined.

this group was about 45\%, which is worse than for many malignancies. Not surprisingly, median survival was negatively influenced by age at onset of stroke in all cohorts. The presence of atrial fibrillation on the first examination also significantly influenced long term survival in the three cohorts, as shown in previous studies. $^{1213}$

\section{Strengths and weaknesses}

The strength of these data rests on the fact that the cohorts were large and well characterised, the baseline data were generally complete, and follow-up was prospective and prolonged, with minimal loss to six month and prolonged follow-up. The scope for selection bias in the assembly of these cohorts was least for the community based Oxfordshire cohort and greatest for the randomised international stroke trial. We did not include 414 patients with ischaemic stroke from the Lothian study because data were collected at one year (instead of six months), but an analysis that included these 414 patients showed no significant differences in overall survival. Hence, the exclusion of these patients did not have a substantial influence on our findings in this cohort. Our analyses are based on the assumption that patients not reported as dead were alive and that official statistics are accurate. Patients who moved abroad after inclusion in one of the cohorts and died while overseas might not have been recorded if the death certificate was not sent to the UK. We also cannot exclude the further possibility that independent survivors might have been more likely, and able, to emigrate than dependent ones. These effects might have led to an overestimation of median survival in all cohorts, though we think the effect would be small because emigration, especially among elderly people, is relatively uncommon. ${ }^{145}$

\section{Relevance of findings}

The consistency across the three cohorts of the effect of the patient's level of dependency on subsequent survival suggests that the relative effects are 


\section{WHAT IS ALREADY KNOWN ON THIS TOPIC}

Several factors influence the outcome of patients with ischaemic stroke and their survival in the early months and years after stroke onset

Little is known on the impact of functional outcome shortly after ischaemic stroke on long term survival

\section{WHAT THIS STUDY ADDS}

Functional status of patients six months after onset of an ischaemic stroke has a significant and substantial effect on their long term survival

Less than half those alive with severe disability at six months will survive five years; a survival statistic comparable with that of several malignancies

Our findings have implications for the estimation of the global burden and costs of stroke, for the planning of health care and research, and in clinical practice

generalisable. A graded effect was evident in the three cohorts, even though there were variations in case mix, time period, and location. Also, the demographics of the three studies suggest that the results are generalisable. The mean age of patients in the three cohorts (ranging from 68 to 73 years) was similar to that in large community and hospital based studies of ischaemic stroke patients. ${ }^{16-22}$ The proportions of stroke subtypes according to the Oxfordshire community stroke project classification in our cohorts were similar to those found in other studies (though there were fewer total anterior circulation infarcts in the Lothian and Oxfordshire cohorts), as were the outcomes in terms of early case fatality and the proportion of patients who were dead or dependent at six months. ${ }^{16-25}$ These cohorts, however, were assembled at a time when secondary prevention in stroke survivors was much less intensive than now. Our analyses of survival during different time periods showed, as one might expect, that survival did indeed slightly improve over time. Hence, when we apply these estimates to current patients, it may be reasonable to assume that on average, at a given level of dependency, median survival would be somewhat better than portrayed here. $^{26}$

We believe that these data have several implications for clinical practice. They can be used to inform patients and their relatives about the prognosis after an ischaemic stroke. They have implications for the estimation of the impact and costs of stroke and for the planning of health care and research. Estimates of global disease burden and costs have so far relied mainly on modelling techniques. Our data could be used to assess the cost effectiveness of treatments for the acute phase of stroke. Previous studies have shown that the costs of long term care account for about half of the total costs of stroke care. ${ }^{27-29} \mathrm{~A}$ health economics model has suggested that treatments that reduce dependency in survivors by only a modest amount might, none the less, have a substantial effect on long term survival free of dependency and hence prove highly cost effective. ${ }^{3031}$ Our data strongly support this hypothesis. Future studies should assess whether early interventions that reduce functional dependency at six months after onset of ischaemic stroke have positive effects on subsequent long term survival, as our study suggests.

We thank the patients who participated in all the studies. We are grateful to Mike McDowall, who has looked after the Lothian and Oxfordshire datasets, and to Sheila Grant, who collated and entered the data on deaths from the three cohorts.

Contributors: PS was the principal investigator for the international stroke trial and played an important role in design, conduct, and analysis of the Oxfordshire community stroke project. PD conceived the idea for assessing the impact of disability on long term survival and established the follow-up mechanism. MD was principal investigator for the Lothian stroke register and coinvestigator for the Oxfordshire project. KBS did the data analysis, drafted the manuscript, and is guarantor. SL supervised all the statistical aspects of the work. EB contributed to the planning of this work and participated in the interpretations of the results. All the authors contributed to design, analysis and commented on drafts of the manuscript.

Funding: The Oxfordshire community stroke project and the international stroke trial were funded by the UK Medical Research Council. Some of the costs of collection of the long term survival data were supported by an unrestricted educational grant from Boehringer Ingelheim.

Competing interests: None declared.

Ethical approval: All studies were approved by relevant local ethica committees.

Provenance and peer review: Not commissioned; externally peer reviewed.

1 Bonita R. Epidemiology of stroke. Lancet 1992;339:342-4.

2 Strong K, Mathers C, Bonita R. Preventing stroke: saving lives around the world. Lancet Neurol 2007;6:182-7.

3 Feigin VL, Lawes CM, Bennett DA, Anderson CS. Stroke epidemiology: a review of population-based studies of incidence, prevalence, and case-fatality in the late 20th century. Lancet Neurol 2003;2:43-53.

4 Bamford J, Sandercock P, Dennis M, Warlow C, Jones L, McPherson K, et al. A prospective study of acute cerebrovascular disease in the community: the Oxfordshire community stroke project 1981-86. 1. Methodology, demography and incident cases of first-ever stroke. J Neurol Neurosurg Psychiatry 1988;51:1373-80.

5 International Stroke Trial Collaborative Group. International stroke trial (IST): a randomised trial of aspirin, subcutaneous heparin, both, or neither among 19435 patients with acute ischaemic stroke. Lancet 1997;349:1569-81.

6 Bamford J, Sandercock P, Dennis M, Burn J, Warlow C. Classification and natural history of clinically identifiable subtypes of cerebral infarction. Lancet 1991;337:1521-6.

7 Van Swieten JC, Koudstaal PJ, Visser MC, Schouten HJ, van Gijn J. Interobserver agreement for the assessment of handicap in stroke patients. Stroke 1988;19:604-7.

8 Lindley RI, Waddel IF, Livingstone M. Can simple questions assess outcome after stroke? Cerebrovasc Dis 1994;4:314-24.

9 Wilson JT, Hareendran A, Hendry A, PotterJ, Bone I, Muir KW. Reliability of the modified Rankin scale across multiple raters: benefits of a structured interview. Stroke 2005;36:777-81.

10 Dennis M, Wellwood I, Warlow C. Are simple questions a valid measure of outcome after stroke? Cerebrovasc Dis 1997;7:22-7.

11 Schoenfeld D. Partial residuals for the proportional hazards regression model. Biometrica 1982;69:239-41.

12 Jorgensen HS, Nakayama H, Reith J, Raaschou HO, Olsen TS. Acute stroke with atrial fibrillation. The Copenhagen stroke study. Stroke 1996;27:1765-9.

13 Lin HJ, Wolf PA, Kelly-Hayes M, Beiser AS, Kase CS, Benjamin EJ, et al. Stroke severity in atrial fibrillation. The Framingham study. Stroke 1996;27:1760-4.

14 Hatton TJ. Emigration from the UK, 1870-1913 and 1950-1998. 2003. www.ecocomm.anu.edu.au/people/info/hatton/EmDubTF. pdf.

15 Office for National Statistics. Implications of the 2001 census report www.statistics.gov.uk/census2001/implications.asp.

16 Carolei A, Marini C, Di Napoli M, Di Gianfilippo G, Santalucia P, Baldassare $M$, et al. High stroke incidence in the prospective community-based L'Aquila registry (1994-1998). First year's results. Stroke 1997;28:2500-6.

17 Ellekjaer H, Holmen J, Indredavik B, Terent A. Epidemiology of stroke in Innherred, Norway, 1994 to 1996 . Incidence and 30-day case-fatality rate. Stroke 1997;28:2180-4 
18 Jamrozik K, Broadhurst RJ, Lai N, Hankey GJ, Burvill PW, Anderson CS Trends in the incidence, severity, and short-term outcome of stroke in Perth, Western Australia. Stroke 1999;30:2105-11.

19 Kolominsky-Rabas PL, Weber M, Gefeller O, Neundoerfer B, Heuschmann PU. Epidemiology of ischemic stroke subtypes according to TOAST criteria: incidence, recurrence, and long-term survival in ischemic stroke subtypes: a population-based study. Stroke 2001;32:2735-40.

20 Lauria G, Gentile M, Fassetta G, Casetta I, Agnoli F, Andreotta G, et al. Incidence and prognosis of stroke in the Belluno province, Italy. Firstyear results of a community-based study. Stroke 1995;26:1787-93.

21 Smadja D, Cabre P, May F, Fanon JL, René-Corail P, Riocreux C, et al. ERMANCIA: epidemiology of stroke in Martinique, French West Indies: Part I: methodology, incidence, and 30-day case fatality rate. Stroke 2001;32:2741-7.

22 Thrift AG, Dewey HM, Macdonell RA, McNeil JJ, Donnan GA. Incidence of the major stroke subtypes: initial findings from the North East Melbourne stroke incidence study (NEMESIS). Stroke 2001;32:1732-8.

23 Johansson B, Norving B, Lindgren A. Increased stroke incidence in Lund-Orup, Sweden, between 1983 to 1985 and 1993 to 1995 Stroke 2000;31:481-6.

24 Dewey HM, Sturm J, Donnan GA, Macdonell RA, McNeil J], Thrift AG. Incidence and outcome of subtypes of ischaemic stroke: initial results from the North East Melbourne stroke incidence study (NEMESIS). Cerebrovasc Dis 2003;15:133-9.

25 Di Carlo A, Lamassa M, Baldereschi M, Pracucci G, Consoli D, Wolfe CDA, et al. Risk factors and outcome of subtypes of ischemic stroke.
Data from a multicenter multinational hospital-based registry. The European community stroke project. J Neurol Sci 2006;244:143-50.

26 Carter KN, Anderson CS, Hackett ML, Barber PA, Bonita R. Improved survival after stroke: is admission to hospital the major explanation? Trend analyses of the Auckland regional community stroke studies. Cerebrovasc Dis 2007;23:162-8.

27 Spieler JF, Lanoe JL, Amarenco P. Costs of stroke care according to handicap levels and stroke subtypes. Cerebrovasc Dis 2004;17:134-42.

28 Gerzeli S, Tarricone R, Zolo P, Colangelo I, Busca MR, Gandolfo C. The economic burden of stroke in Italy. The EcLIPSE study: economic longitudinal incidence-based project for stroke evaluation. Neurol Sci 2005;26:72-80

29 Kolominsky-Rabas PL, Heuschmann PU, Marschall D, Emmert M, Baltzer N, Neundörfer B, et al. Lifetime cost of ischemic stroke in Germany: results and national projections from a population-based stroke registry: the Erlangen stroke project. Stroke 2006;37:1179-83.

30 Samsa GP, Matchar DB. Have randomized controlled trials of neuroprotective drugs been underpowered? An illustration of three statistical principles. Stroke 2001;32:669-74.

31 Samsa GP, Reutter RA, Parmigiani G, Ancukiewicz M, Abrahamse P, Lipscomb J, et al. Performing cost-effectiveness analysis by integrating randomized trial data with a comprehensive decision model: application to treatment of acute ischemic stroke. J Clin Epidemiol 1999;52:259-71.

Accepted: 21 November 2007 